\title{
Christian Madsbjerg's Sensemaking: The Power of the Humanities in the Age of the Algorithm
}

\author{
Alexander Franco, Ph.D. \\ Stamford International University, Graduate School of Business \\ alexander.franco@stamford.edu
}

Received Date: July 7, 2017

Accepted Date: July 10, 2017

Published Date: July 17, 2017

The objectives of this work were twofold: The first was a call for a return to educating business leaders in the fields of humanities and social sciences in order to combat the rise of algorithmic intelligence which the author argues lacks the ability to produce contextual analyses that can comprehensively understand and interpret perspective and meaning. The second objective was to offer phenomenology as the methodological orientation to analyze the context of business situations as phenomena, which can then provide greater insights leading to viable solutions.

The author, a management consultant, creates a construct which he names "sensemaking" and which he defines as "wisdom grounded in the humanities" or "the exact opposite of algorithmic thinking" (p. 6). The bulk of the book is structured to present the five principles that make up sensemaking: 1) culture - not individuals; 2) thick data - not just thin data; 3) the savannah - not the zoo; 4) creativity - not manufacturing, and; 5) the North Star - not the GPS. These five principles are discussed below.

The first principle argues that focusing on individual behavior decontextualizes human action since such action can only be adequately analyzed through a larger cultural context, or as the author states, "[n]othing exists in an individual vacuum" (p. 11). Principle 2 discusses "thick data," by which the author is referring to looking beyond the what of a phenomenon [i.e., algorithmic empirical data collected - or "thin data stripped of all its organic life" (p. 16)] and, instead, the why of what is happening through a holistic synthesis of the data. Principle 3 calls for analysis of true social contexts that cannot be found in abstract numbers. The author uses the metaphor of the savannah versus the zoo, or "watching a pack of lions hunt on the actual savannah" as opposed to "seeing them get fed from a bowl at the zoo" (pp. 16-17). Principle 4 emphasizes creative thinking or abductive reasoning, which the author defines as "non-linear problem solving" (p. 19) over traditional approaches of inductive or deductive reasoning. The last principle uses the analogy of following the north star over GPS to argue against reliance on the acquisition of information without being able to understand how it was collected and without acquiring the ability to interpret "new and unfamiliar contexts" (p. 22). The author concludes by stating that these five principles can be operationalized by apply phenomenology as an analytical tool which he believes is context-sensitive. He argues that studying human experiences within a cultural context creates an "analytical empathy" (p. 116) that better helps to explain the complexities of the world.

It is important to note that the author is not a neo-Luddite; this work does not regret technological advances in algorithmic intelligence and it is devoid of the gloom and doom found in many contemporary works regarding a technological future. It is an important work because of its advocacy of foundational knowledge in the humanities being acquired by business leaders. Indeed, a similar argument can be made for everyone. The 
author laments that such education is being bypassed for technical training, beginning at the bachelor level of higher education. This work argues that without a philosophical framework and a meaningful methodological approach to analyzing the world, we are at a loss to understand and solve complex problems in the business world and beyond.

Such an advocacy is welcomed and missed in recent works by Martin Ford (2015), and Ryan Avent (2016), to give just two examples, that examined the challenges of a technological future only to advocate redistribution of wealth and guaranteed income schemes. Madsbjerg succeeds where they failed. He declares that algorithmic intelligence, whether from a super computer or a future humanoid robot, will never be able to replicate the thinking of humans. The author implies that the soul of a human being, in the non-supernatural sense, constitutes the unique crystallization of life experiences, emotion, knowledge, and contemplation that, in turn, generates innovation, creativity, intuition, and the ability to examine human action in depth and with empathy. Computers and robots, at best, can be invested with bits and pieces of human souls but in the aggregate, can never replicate genuine self-awareness or a conscience through a computational process. Good ideas are golden currency that algorithms cannot mint. The author argues that the depth of our souls depends on exposure to the richness offered by studying art, the humanities, and the social sciences. Only through this exposure can we develop a meaningful philosophical sense of life.

If the author had focused solely on this message, this book would have been sound and laudable, albeit somewhat short. However, Madsbjerg then reached into the realm of the social sciences and made an unfortunate selection in the methodology to be used for business analyses. This is where this work became problematic to the point of unintended self-sabotage.

The author argues that individuals should always be viewed as "situated in a context" and, therefore, human behavior cannot be understood without understanding the context itself - "an argument for the holistic versus the atomized" (p. 49). To accomplish this, he chose phenomenology as the methodological tool to accomplish context-sensitive analysis. This presents several problems. Firstly, phenomenology, like most residents in the postmodernist realm, lacks a clear definition. Pure phenomenology views subject matter as autonomous and, unfortunately, that epistemic isolation renders it operationally useless for analytical endeavors. More practical manifestations of phenomenology still suffer from weak metaphysical foundations, let alone ontological considerations, and these weak foundations, in turn, are responsible for anemic analysis or outright inertia as a result of profound epistemic uncertainty.

Phenomenology argues that contemplation of human experience is primary for understanding since what truly matters is how things are seen. This is problematic in that humans lack a detailed, internal representation of any given scene. Experiential meanings (i.e., how things seem to a person) are not enough for any robust analysis since psychological observation and personal meditation cannot pass for logic. Phenomenology leaves the back door open for ambiguity, subjectivity, and indeterminacy while discouraging empirical inquiry and rejecting metaphysical assumptions as well as epistemic commitments.

Worse, the author then crowns Martin Heidegger as our future philosopher king. Heidegger is mentioned no less than twenty-four times in the book and it is from Heidegger's opaque writings (mostly Being and Time) that the author derives his favorite version of phenomenology. A major problem with this choice is that Heidegger was a devoted Nazi, known to have delivered lectures on biological stock and racial superiority while proudly wearing a brown shirt and his party badge. A personal friend to Eugene Fischer, director of the Berlin Institute for Racial Hygiene, Heidegger served as rector of Freiburg University where he cooperated with the local 
Gestapo in pro-actively providing information about Jews and non-conformists to the Nazi regime within the university setting. This included his one-time mentor, Edmund Husserl, who was a Jew and from whom Heidegger obtained fundamental insights regarding phenomenology. Without Edmund Husserl, there would not have been a Martin Heidegger.

Heidegger created a legacy of sexually exploiting his students, including Jews (Hannah Arendt being one) as a pattern of marital infidelity that spanned much of his life. He believed that national socialism required a philosopher king and offered himself to this role. However, his support for Hitler began to wane when the Nazis did not take this offer seriously. Unrepentant to the end, Heidegger was incriminated for association with the regime and was banned from teaching from 1946 to 1950.

Why is all this important? Because the author of this book and others would undoubtedly argue that it is possible to separate a man's politics from his philosophy or, specifically, that Heidegger's philosophical worldview was not Nazi with regard to phenomenology (which he developed before Hitler came to power). The problem is that politics is indeed a branch of philosophy and one heavily depend on three other branches: metaphysics, epistemology, and ethics. These three in combination provide an integrated view of man's nature, his relationship to existence, and what is morally justifiable - specifically in politics, what is morally acceptable regarding the use of the coercive powers of the state. Heidegger's philosophical sense of life, including his emphasis on the importance and supremacy of the Germanic community, was based to a great extent on racism. The metaphysics of racism is so self-evident in its corruption that it becomes easier to understand how Heidegger's epistemic construction of phenomenological inquiry is so flawed and why phenomenological research methods have been limited to eccentric philosophical journals. The link is not to suggest that phenomenology is a Nazi construct; the link is in the weaknesses in Heidegger's overall philosophical worldview and its consequential epistemic constructs.

This reviewer is not the first to say that this emperor had no clothes. That Heidegger is not worthy of becoming our philosopher king is also self-evident by phenomenology's very limited appeal and almost no utilitarian value in academia. It is an intoxicating elixir for mediocre philosophers in that it offers the ingredients of being anti-modern and contemptuous of the common man (thus giving the philosopher a false sense of superiority) while at the same time being ephemeral (like embracing fog), and kaleidoscopic, thus making it a difficult moving target to hit, beginning with an ambiguous definition that remains a domain for substantive dispute. As with the concept of postmodernism, to be invited to debate its substance is akin to being invited to a party where you are asked to dive off the deep end of a pool with no water.

This reviewer is not linking the author with Heidegger's politics. The author was educated at a time when postmodernism was (and still is) the prevailing zeitgeist in the social sciences. He undoubtedly chose within the limitations of what he was exposed to. A better choice as a context-sensitive methodological orientation would have been dialectics. Dialectic analysis, which has been around since the time of Aristotle, is a methodological orientation that transcends ideology. In being contextual, relational, and dynamic, it allows for a multidimensional and integrative means to a critical understanding of a given phenomenon. Dialectics is contextual because it relates specific factors to their wider context; it is relational because it traces interrelations between and among factors; it is dynamic because it examines factors in terms of their movement over time. Dialectics refuses to isolate or disconnect factors, events, or issues from one another or from any system they jointly constitute. It recognizes a past, present, and a future by way of antecedent conditions, the dynamics of interrelationships, and projected consequences. Its practicality is in operationalizing an analytical strategy of contextually grasping parts within larger totalities. 
On a final note, the author illustrated the five principles of sensemaking by using mini-case studies and anecdotes. He profiled George Soros for his mastery at being able to "simultaneously synthesize inputs of inconceivable complexity" (p. 80) as an example of utilizing "thick data" over "thin data." This flattering profile went on for nearly three pages where the author informs us that Soros "trained himself to rigorously stay open to all types of knowing" (p. 83). This is astonishing and ironic given that Soros was convicted in 2002 of insider trading regarding the takeover of SocieteGenerale, a French bank. Why Soros would be picked at all as a laudatory figure in this book is troubling. As an adolescent, Soros (of Jewish descent) collaborated with Nazis during World War II in helping them confiscate property from Jews that Soros identified. Soros has described this as the happiest time of his life. Later, as a currency speculator, Soros helped orchestrate the Asian Financial Crisis of 1997 in which the Malaysian ringgit lost forty-five percent of its value and the Thai baht lost sixty percent, sending those two nations into an economic death spirals of unemployment, bankruptcies, massive poverty, and suicides. The prime minister of Malaysia labeled Soros a villain. In 1992, Soros crashed the British pound, causing the British government to lose over three billion pounds. The combination of these actions suggest that this man is, at the very least, knocking on the door of sociopathy.

The choices of Heidegger for philosopher king and Soros as a virtuoso of business are, indeed, unfortunate. They diminish the gravitas needed for the author's worthy crusade and may even cause many to ignore his clarion call to champion the return to a robust educational background in the humanities and social sciences for future business leaders. Perhaps the moral of this story may be that the value of a liberal arts education is only as good as the diversity of ideas to which it exposes to students.

\section{References}

Avent, R. (2017). The wealth of humans: Work and its absence in the twenty-first century. London: Penguin Random House UK.

Ford, Martin. (2015). The rise of the robots: Technology and the threat of mass unemployment. London: Oneworld Publications.

Sensemaking : The Power of the Humanities in the Age of the Algorithm

Christian Madsbjerg

New York: Hachette Books 2017

Citation: Alexander Franco, Christian Madsbjerg's Sensemaking: The Power of the Humanities in the Age of the Algorithm. American Research Journal of Business and Management; V3, I1; pp:1-4

Copyright (C) 2017 Alexander Franco, This is an open access article distributed under the Creative Commons Attribution License, which permits unrestricted use, distribution, and reproduction in any medium, provided the original work is properly cited. 